\title{
KNOWLEDGE OF CYPRIOT STUDENTS OF SOCIAL WORK ABOUT AIDS
}

\author{
Stefanos Koffas ${ }^{1}$ *, Eleni Tsolaki ${ }^{2}$ \\ ${ }^{1}$ Frederick University, Department of Social Work, Cyprus \\ ${ }^{2}$ Frederick University, General Department, Cyprus \\ ${ }^{*}$ Corresponding Author
}

\begin{abstract}
The current research endeavours to identify the knowledge of students of Social Work about AIDS in relation to how it influences their lives on issues of social prevention. It is specifically focused on matters of behaviour and attitudes towards health protection (sexually transmitted diseases); it explores practices that the students, with their special education, use to identify the risks they are exposed to in order to take precautions and consequently to prevent serious situations that may lead to insurmountable problems decisive for society. The method used for data collection was structured questionnaires. The investigation results are presented with the formulation of specific research hypotheses/questions, which were examined by using the method of qualitative data analysis. Taking into consideration that the total sample consisted of a small number of men and a large number of women, who then reported to have sexual relations, as well as society's tendency that encourages men to brag about their sexual conquests while almost stigmatizing women, overestimation for males and underestimation for females cannot be excluded. The conclusion of the research's results shows that young adult students seem quite knowledgeable about their sexuality, protection measures and the risks at hand. At the same time though there are several deficiencies related to the source and transmission of correct knowledge which need to be covered. Additionally, it emphasises the prevalent mentality in conjunction with the influence that the family has in Cyprus, since parents function as powerful role models for their children.
\end{abstract}

Keywords: AIDS, Sexually Transmitted Diseases, Knowledge, Attitudes, Health Protection

\section{INTRODUCTION}

Each source of information is a weapon against disease and a valuable ally in changing hazardous attitudes and problematic perceptions. Correct information and education are crucial elements in the fight against AIDS so as to limit fear and prejudice and, just as important, to reinforce proper prevention.

It is based on these convictions that the social profile of social work students in Cyprus is presented in regard to their knowledge and the practices they apply in their personal life, where AIDS is concerned, and the important role they will play as future professionals in information campaigns. More specifically, we are trying to determine their knowledge of the principal epidemiologic parameters in the spread of the virus, the personal behaviour they exhibit on issues of prevalence of the disease through sexual practices and their sensitivity on issues of correct education and prevention. 


\section{REREARCH METHODOLOGY}

\subsection{Methodology Used (Tools for Data Collection, Processing and Analysis)}

Having collected the questionnaires, the answers were coded and the resulting data was analysed using the SPSS 20 statistical software. Most of the data is categorical and some of that is ordinal (Creswell, 2003). There is only a small number of numerical data which comes mostly from questions rating the respondents' knowledge.

The questions were studied using mainly descriptive statistics, i.e. by recording the percentages of each category since the data is mostly qualitative, before conversion into quantitative. Percentages were calculated for all questions after the number of individuals that did not respond (missing observations) (DeVaus, 2008, pp. 3-5; Crotty, 2004, pp. 2-3) were removed from the sample.

The small number of participants in the research was the reason why cross-checked multivariable comparisons were not possible. This is the case as "no more than $20 \%$ of the expected counts are less than 5 and all individual expected counts are 1 or greater" (Yates, Moore \& McCabe, 1999, p. 734).

\subsection{Research Questions}

The main question, given to all participants in the current study, is whether their knowledge and practices to protect their health are effective or not, which as a consequence may have influenced the health behaviour of young adults and in which direction. The specific research question focuses on exploring knowledge as the outcome of correct information on health improvement, in order to reveal what measures were taken, whether they were effective or need yet to be taken in that direction.

The objectives of the research focus on determining what young social work students practise in their sexual life and to highlight their concerns; how valid is the information they have about the danger of certain sexual practices and what kind of risks they take and, additionally, to present the correct knowledge about infection and prevention which needs to be covered.

\subsection{Questionnaire and Sample}

The research was concluded in 2014. It was addressed to a large sample of undergraduate and graduate students, who were asked to participate voluntarily by filling out a structured questionnaire. The questionnaire was developed by the Mediterranean Research Lab of Public Health and Quality of Care of the Nursing Department of the Technological University of Cyprus.

The questions were mostly closed-ended in order to get answers while narrowing down their field and, additionally, help the researcher in analysing the data more easily (losifidis, 2003). More specifically, the questionnaire includes scaled evaluation questions (using the 5-point Likert scale) (Patton M., 1990, pp. 169186; Dunn 2000).

The questionnaires were handed out in person to 120 individuals. An important factor causing unwillingness to fill out the questionnaires was the very personal nature of the questions concerning the sexual behaviour of the participants, but also the large number of questions. Taking into consideration the large difference between men and women that reported to have sexual relations, as well as society's tendency that encourages men to brag about their sexual conquests while almost stigmatizing women, overestimation for males and underestimation for females cannot be excluded.

Participants come from the free areas of all five provinces of the Republic of Cyprus. The selection of participants in the research was based on simple random sampling and does not follow specific sampling criteria by strata, clusters or levels. Representation of large urban centres and areas with smaller population is also random, but is to a significant extent proportionate (Rousos \& Tsaousis, 2011, pp. 135-136).

\section{RESULTS}

Of the total questionnaires distributed to students of social work 59 were completed in the end. In regard to the demographic characteristics of the sample and in order to draw conclusions from them, participants were asked to provide some information concerning gender, age and marital status. The results demonstrated that the bulk of the research participants (95\%) are young adults between 18 to 24 years of age, with the largest part being individuals up to 22 years of age. The majority of the participants are women $(83.1 \%)$ and $16.9 \%$ are men. The big difference between the genders can be explained by the fact that this field of studies holds a greater appeal for women than men. Their marital status, considering their young age, is $83.1 \%$ single, $8.5 \%$ cohabit with their partner, while $6.8 \%$ are married despite their young age. $71.2 \%$ live with their families, $18.6 \%$ live occasionally with their partner, $8.5 \%$ live alone and $1.7 \%$ answered "other". 
Questions on the participants' sexual life were answered by individuals who have complete sexual relations; they derive information in regard to the frequency and type of sexual practices, the type of relationships they have, the number of sexual partners they have had and whether they use protection measures during sexual activity.

The vast majority of those who have complete sexual relations identify themselves as heterosexual at a rate of $96.6 \%$. A small percentage of $3.4 \%$ gave no answer. In answer to the question who they would trust to tell that they are HIV positive, $62,7 \%$ state they would trust their family, $23,7 \%$ their friends and only $13,6 \%$ answered that they would reveal it to no one. This finding is important "because it is indicative of the strong ties between family members in Cyprus" (Koffas \& Tsolaki, 2016, p.5) and the considerable trust that exists in their relationship, especially in times of hardship that require assistance and support.

Regarding their knowledge about where they can be screened for AIDS, 69.5\% state that they are aware of the appropriate services, while $30.5 \%$ do not know where they should go. This finding indicates a serious information deficiency, as despite the fact that the specific field of studies deals with counselling and information, almost one third of the students are not aware of the appropriate services screening for AIDS. Furthermore, the majority of $86,4 \%$ have not been tested for HIV over the past 12 months, while only a small $13,6 \%$ state that they have. Yet of those reporting that they had a screening test only $11.8 \%$ collected the results, $10.2 \%$ were not interested in collecting them and $78 \%$ did not answer the question.

Analysis showed that in regard to the sexual activity of the last 12 months the rates of protection during sexual intercourse (oral, vaginal, anal) with purchasing and using a condom were only $32.2 \%$, while $57.6 \%$ did not purchase/use a condom. Additionally, $10.2 \%$ stated that it was given to them by someone else. Their sexual relations over the past 12 months show that the majority of both men and women had 1 to 2 sexual partners. More specifically, from the students of the total sample who answered to this question, $82.9 \%$ of women stated that they had sexual relations with one man and men stated the same at a rate of $50 \%$. Women that reported having had sex with two men were $12.2 \%$ and men stating having had sex with two women were $16.7 \%$. Rates are lower for those stating sexual relations with more partners. As such, both genders at an equal rate of $3.4 \%$ report sexual relations with 3 partners over the past 12 months. It should be noted that these results should be approached with caution for reasons related to the predominant social picture concerning the status of the two genders in Cypriot society, as well as the freedom of sexual expression in patriarchal and conservative societies (Koffas, 2014, p. 4; Koffas \& Tsolaki, 2016, p. 2). At this point, it should be made clear that there are no data on the sexual orientation of relations, i.e. heterosexual or homosexual.

When studying the knowledge on sexual behaviour, the type of relationships that students engage in is very important. At that age elements of heightened sexual activity co-exist, usually within brief relationships, which are soon replaced by new ones. Furthermore, elements of curiosity and experimentation are intensified, as well as seeking and having new experiences, even showing off and being original. This is so, as among the numerous factors that shape the sexual behaviour of the youth, other than their developing reproductive ability, some of the most important factors are their propensity to imitate adults, the intense prominence of various sexual role models (http://www.aristsigris.gr) in mass media and the lack of correct information.

Consequently, the current types of relationships should take into consideration their duration and type as elements that reflect the actual sexual behaviour of students. Hence, there are significant differences to the question as to the type of partner, i.e. permanent, casual or paid. Of those reporting that they are in a permanent relationship, $78 \%$ state that it is with a permanent partner with whom there is a mutual commitment of exclusive sexual relations. To the same question, $16.9 \%$ state that despite a permanent partner, there is no mutual commitment of exclusive sexual relations. $11.9 \%$ report to have a casual partner with whom they occasionally have sex with, without any further commitments. A small rate of $3.4 \%$ mentioned a partner involving the exchange of money, i.e. paid sex.

Further analysis of the answers reveals that even though the questionnaire provided a clear definition of a permanent partner, a number of respondents who have a permanent partner make no commitments as to the exclusiveness of sexual relations and have a casual partner too. "This fact is related to how long a relationship lasts and hence what participants consider a permanent relationship. We cannot ignore the fact that at these ages relationships often last a short time, resulting in frequent breakups and the subsequent frequent moving on to new partners, but always in the context of a permanent relationship" (Koffas \& Tsolaki, 2016, p.5).

The use or not of condoms was examined next, during the various types of practices engaged in by the respondents, i.e. vaginal, anal and oral sex during sexual intercourse. $5.1 \%$ reported to use condoms during 
oral sex in contrast to $52.5 \%$ who answered negatively to this question. $5.1 \%$ stated to use condoms during anal sex in contrast to $33.9 \%$ who do not. Lastly, $42.2 \%$ reported to use condoms during vaginal sex, while $39 \%$ do not. The numbers of those not providing answers to these questions are quite high and range between $42.5 \%$ in the case of oral sex, $61 \%$ for anal sex and $18.6 \%$ for vaginal sex. The answers exhibit the existence of different practices in the use of condoms. During oral and anal intercourse, the majority of those answering the question reported, to a significant proportion, that they do not use condoms. The results are quite opposite in the case of vaginal sex. These findings are considered significant from a clinical point of view as they relate to sexually transmitted diseases and, unfortunately, indicate that the participants engage in high-risk behaviours. Furthermore, the fact that participants use condoms during vaginal contact might indicate that it also constitutes a contraceptive measure against unwanted pregnancies, which however cannot be corroborated.

The largest percentage of respondents (49.2\%) does not provide an answer as to why they do not use condoms. For those who do, it seems that there is a number of different factors related to non-use. More specifically and in descending order, $22 \%$ state lack of satisfaction/pleasure during sexual intercourse, $11.9 \%$ that they are in a permanent relationship and do not consider it necessary, $6.1 \%$ because they did not have one with them at the time, $5.1 \%$ for other reasons, 3.3\% because they forgot it and $1.7 \%$ because they do not know how to use it. For this question, as well, findings bear significant clinical value since they highlight deficiencies in prevention practices and the taking of risk by the participants.

Answers to questions on matters of awareness, prevention and behaviour in regard to sexually transmitted diseases are in many cases correct, without however the rates being quite satisfactory and including high percentages of respondents who are unknowledgeable. Thus, $74.6 \%$ state that they can be protected by using condoms, $78 \%$ believe that they can protect themselves by being in a loyal relationship, $69.5 \%$ are aware that they cannot be infected with HIV by a mosquito bite, however $13.6 \%$ do not know and $15.3 \%$ answered "yes". The use of shared cookware and tableware with an HIV positive individual does not pose a risk of infection for $74.6 \%$ of the participants, in contrast to $11.9 \%$ that support that there is a risk of infection and $11.9 \%$ who reported not to know.

Correlating the non-use of condoms and the risk of HIV infection through specific sexual practices, the majority of the participants report high risk rates. More particularly, oral sex is believed to pose less than $50 \%$ risk of getting infected for $53.1 \%$ of the sample, while higher rates are reported by the remaining $46.9 \%$. In relation to anal sex, $16 \%$ of the sample believes that risk of infection to be less than $50 \%$, while $84 \%$ of respondents believe risk of infection to be higher. For vaginal sex, $9.4 \%$ believe that risk of infection is less than $50 \%$, while $90.6 \%$ indicate higher infection risk rates.

The participants' self-evaluation of their knowledge regarding HIV transmission and prevention is generally high. Only $18.6 \%$ consider that their knowledge is limited and give themselves up to $5 / 10$. The highest selfevaluation score at a rate of $27.1 \%$ of the total number of respondents is $8 / 10$. One third $(32.2 \%)$ rate their knowledge between 6 and 7, while $22.1 \%$ evaluate themselves with excellent scores ranging between 9 and 10. What is worth highlighting for these results is that of maybe the extreme confidence placed by young individuals in what they consider permanent relationships for not using protection measures: also, the fact of significantly high rates of self-evaluation, which however are in partial contrast to the previous questions on awareness and protection measures.

The majority has heard about AIDS from various information sources with the biggest part coming from school $(79.7 \%)$, parents follow with $6.8 \%$, television with $5.1 \%$, the internet with $5.1 \%$ and $3.4 \%$ from other sources. It seems that the role of education on matters of sex education/information is very significant, since it is the primary information source.

The influence of the individuals the young people are in close contact with is also revealed to be significant; it is known to affect the development of young people's personality by causing specific behavioural reactions, since they function as powerful role models to identify with (Tountas, 2000, pp. 216, 221). To the question concerning who they spend more time with they respond the mother by $81.4 \%$ and less the father at $10.2 \%$, while the grandmother and aunts follow at $3.4 \%$ and $1.7 \%$ respectively. Despite the mother being the person closer to her child, still she does not seem to know much about its activities outside the family home. This becomes clear in the next question where young people are asked to answer whether the person they spend a lot of their time with is aware of where they go, with whom, what they do after university classes, who are their friends, how they spend their money. The response rates in the category "knows a lot" for the subquestions "where do you spend the night", "what do you do in your free time", "who are your friends", "how do you spend your money" may be high, but concern only $50 \%$ of the sample, as half did not provide answers. The remainder does not seem to inform or provide explanations for very personal behaviour aspects even to their mothers. 


\section{CONCLUSION}

The investigation of the opinions and behaviours of students of social work in regard to AIDS, which is carried out in the current study is particularly important; students are part of the sexually active population and as such reflect the opinions and behaviours of others in the social groups they come from. At the same time, the investigation of behaviours is an element through which the education programme can be evaluated in regard to the knowledge and information provided on matters concerning prevention and promotion of health.

By evaluating the answers of students constituting the sample of the current study we ought to highlight the element of confusion and uncertainty on certain important practices. More specifically, the interpretation of the results reveals that students of social work seem to possess adequate knowledge of sexuality, means of protection and the existing risks. At the same time, though, there are considerable deficiencies related to the source and way of transmission of correct knowledge which should be covered. What becomes clear in regard to information sources is the importance of the accuracy of targeted information by specialists.

Furthermore, the sexual practices of young students pose significant risk. The frequent changing of sexual partners, even within the context of permanent relationships, seems to function as a risk factor, since protection measures are not used as they should be. Additionally, protection is mostly used during certain sexual practices (usually vaginal sex) and unfortunately increases risk as it has been proven to be a misguided habit. Indeed, non-use of condoms in casual relations constitutes the apex of, at least, irresponsible and irrational behaviour as it also entails the risk of spreading a possible infection.

Those are very basic elements of confusion in regard to appropriate and safe sexual behaviour that should not really exist; especially in the case of future professionals who are part of a very important link in the chain of information for others, because of their profession and their interventions at an individual, group, but also community levels.

\section{REFERENCE LIST}

Creswell J.W. (2003). Research Design: Qualitative and Mixed Methods Approaches, London, Sage.

Crotty M. (2004). The Foundations of Social Research: Meaning and Perspective in the Research Process, London, Sage.

DeVaus D. (2008). Analysis of Social Data: 50 Fundamental Issues, Athens, Publications Ellinika Grammata. (In Greek)

Dunn K., (2000). "Interviewing", in Hay I., Qualitative Research Methods in Human Geography, South Melbourne, Oxford University Press.

Iosifidis Th., (2003), Analysis of Qualitative Data in Social Sciences, Athens, Kritiki Publications. (In Greek)

Koffas S. (2011). "Trends and Particularities in the Practice of Social Policy in Greece and Germany: The Effect of Culture and Mentality as Factors of Different Thinking and Action in the Practice of Social Policy Models", Athens, Social Work, 104: 199-221. (In Greek)

Koffas S. (2014). "Health Policy and the Co-Perception of Individual Responsibility in the Neo-Liberal Model", Social Work, SKLE, Athens, Vol. 115, pp. 25-40. (In Greek)

Koffas S., Tsolaki E., (2016). "Knowledge and attitudes of Cypriots students on their sexual life" in International Journal of Social Work and Human Services Practice, 2016, Vol. 4 No.1, pp.24-31, DOI: 10.13189/ijrh.2016.040104.

Patton M. (1990). Qualitative Evaluation and Research Methods, Beverly Hills, CA, Sage, pp. 169-186.

Rousos P.L., Tsaousis G. (2011). Statistics in Behaviour Sciences Using SPSS, Athens, Topos Publications. (In Greek)

Yates D., Moore D., McCabe G. (1999). Practice of Statistics: Advanced Placement, $1^{\text {st }}$ ed., New York: W.H. Freeman, p. 734.

Tsigris A. (2013). epidemic among teenagers get the sexually transmitted diseases. http://www.draristsigris.gr/news/29/diastaseis-epidimias-metaxu-ton-efivon-pairnoun-ta-sexoualikosmetadidomena-nosimata 